\title{
POLYCHAETES AS BIOINDICATORS OF ENVIRONMENTAL POLLUTION: IMPACT OF BISPHENOL A ON THE REPRODUCTION RATE OF OPHRYOTROCHA DIADEMA (ÅKESSON, 1976) (EUNICIDA: DORVILLEIDAE)
}

\author{
Stefano Ruberto*, Daniele Buono and Alfredo Santovito
}

Department of Life Sciences and Systems Biology, University of Turin, Turin, Italy

*Corresponding author. Email: ruberto.ste@gmail.com

\author{
Article history \\ Received: 25 March 2021, \\ accepted 01 June 202
}

Keywords:

BPA; polychaetes; Ophryotrocha; marine invertebrates; reproductive function

\begin{abstract}
Bisphenol A (BPA) is one of the most used additives in the production of many plastic products and may be released into the environment by commonly used products, such as food containers and polycarbonate bottles. BPA is recognized as an endocrine disruptor able to produce adverse effects on the reproduction system of benthonic and pelagic species. Polychaetes of the genus Ophryotrocha are small worms living amongst the interstitial fauna in nutrient-rich and polluted habitats. Owing to easy rearing in the laboratory and short generation times, this species is a useful model organism for studying different biological aspects. This study describes the effects of different BPA concentrations on egg production in Ophryotrocha diadema. We tested six different concentrations of BPA in a 5-week experiment. Strong negative correlation between BPA concentrations and the number of eggs produced was found. The $t$-test revealed a significant reduction in egg production after exposure to BPA concentrations over $1461.1 \mu \mathrm{g} / \mathrm{L}$. The latter concentration value is higher than that observed in the marine environment, although for many species of crustaceans, echinoderms and isopods, the impairment of reproductive function was observed even at much lower BPA concentrations.
\end{abstract}

\section{INTRODUCTION}

Bisphenol A (BPA) is an important synthetic compound used as an additive in the production of polycarbonate plastics, epoxy resins, phenol resins, polyesters and polyacrylates. It is estimated that the global consumption of BPA was 7.7 million tons in 2015 and 8 million tons in 2016, and its production is expected to reach 10.6 million tons in 2022 (PlasticEurope 2016). A wide range of common use products contain BPA, including food packaging materials, water and baby bottles, toys, internal coatings of cans and drums, water pipes, medical and dental devices, and household electronics (Diamanti-Kandarakis et al. 2009).

The main source of BPA in the environment is represented by wastewater from industrial and municipal treatment plants, where this compound was found at concentrations ranging from 59 to $370 \mu \mathrm{g} / \mathrm{L}$ (Fukazawa et al. 2002). In a study conducted in 10 different landfill leachate sites in Japan, Yamamoto et al. (2001) reported very high levels of BPA reaching values of $5.400 \mu \mathrm{g} / \mathrm{L}$ and $17.200 \mu \mathrm{g} / \mathrm{L}$ (Flint et al. 2012). In the Naples Gulf and at the mouth of the Tiber River (south Italy), BPA has been found in concentrations ranging from 0.98 to $26 \mathrm{ppm}$; in two of their most important commercial fish species the percentages of fish found to be BPA- polluted ranged from $60 \%$ (for bass) to $90 \%$ (for mullet) in Latium sea area (Mita et al. 2011).

BPA is a 17b-estradiol homolog and has been recognized as an endocrine-disrupting chemical (EDCs) able to impact several functions related to reproduction and sexuality. In the terrestrial isopod Porcellio scaber (Latreille, 1804), for example, BPA has been shown to harm female reproductive allocation by increasing abortion rates (Lemos et al. 2010). Moreover, in zebrafish, males treated with BPA showed an anomalous development of male gonads, a decrease of serum androgen levels and the number of sperms, an increase of motility in the epididymis, apoptosis and sperm DNA damage (Wintgens et al. 2003; Meeker et al. 2009; Chen et al. 2015; Karnam et al. 2015; Zhuang et al. 2015; Xie et al. 2016; Zhang et al. 2016). Finally, in mice, exposure to BPA decreased fertility and fecundity rates (Cabaton et al. 2011), inducing an earlier onset of puberty in female offspring (Durando et al. 2006).

In the present study, we aimed to evaluate in a 5-week exposure experiment the effects of six different concentrations of BPA on the reproduction of Ophryotrocha diadema (O. diadema), a hermaphrodite marine polychaete. The choice to analyze the effects of BPA on this organism is due to the fact that it is a small worm living in interstitial habitats in nutrient-rich and polluted 
waters, such as harbours. For this reason, it is plausible that this species may have evolved genetic mechanisms able to provide greater resistance to pollutants. Therefore, the eventual negative effects on the reproductive capacity observed in this polychaete could be amplified in other organisms living in less anthropized areas and that, consequently, are less adapted to polluted environments.

Moreover, due to easy rearing in the laboratory and short generation times, several of about 40 polychaetes species currently described are model organisms for studying different biological aspects, including reproductive biology. Indeed, the life cycle of this polychaete lasts several weeks, and the reproductive rates may be very high, allowing a rapid population response to any changes in the environment, including the increase of pollutants concentration (Cannarsa et al. 2015).

\section{MATERIALS AND METHODS}

The outcrossing polychaete $O$. diadema lives among the organic sediments of fouling fauna of harbours, in low-density populations (about 1 individual per $300 \mathrm{~m}^{2}$ ) (Sella and Cristina Lorenzi 2000). Polychaete worms were found in clusters of mussels in nutrient-rich waters of harbours. The sampling was carried out along the coast of Porto Empedocle (Sicily, Italy; 37 $17^{\prime} 04.0^{\prime \prime} \mathrm{N}$; $\left.13^{\circ} 31^{\prime} 42.7^{\prime \prime} \mathrm{E}\right)$ during the summer 2017. In Figure 1, two adult specimens of $O$. diadema sampled in the area of Porto Empedocle are shown. The life cycle of $O$. diadema is represented by a brief male phase that precedes the simultaneous hermaphroditic phase. Mating occurs preferentially between simultaneous hermaphrodites after a lengthy courtship and is achieved by external fertilization in which partners maintain close physical association prior to the synchronous release of gametes (Lorenzi and Sella 2008). In isolated pairs, partners regularly alternate sexual roles by taking turns at laying a cocoon of 20-25 eggs every 2 days on average. Nine days after egg laying, offspring are released from the cocoon as small 4-segment individuals, soon ready to produce their first sperm. When worms reach a body length of 14-17 segments they become simultaneous hermaphrodites: they produce sperm in the fourth and fifth segment and eggs in the following segments (Lorenzi and Sella 2008).

BPA (Sigma-Aldrich, Milan, Italy) was initially dissolved in water at a concentration of $1 \mathrm{mM}$ and successively diluted in order to reach the final used concentrations. In a five-week experiment, we tested six different concentrations of BPA, including the concentrations range observed in wastewater from industrial and municipal treatment plants (Fukazawa et al. 2002): $0.2 \mu \mathrm{M}$ $(45.7 \mu \mathrm{g} / \mathrm{L}), 0.4 \mu \mathrm{M}(91.3 \mu \mathrm{g} / \mathrm{L}), 0.8 \mu \mathrm{M}(182.6 \mu \mathrm{g} / \mathrm{L})$, $1.6 \mu \mathrm{M}(365.3 \mu \mathrm{g} / \mathrm{L}), 3.2 \mu \mathrm{M}(730.5 \mu \mathrm{g} / \mathrm{L})$ and $6.4 \mu \mathrm{M}$ $(1461.1 \mu \mathrm{g} / \mathrm{L})$.

Each BPA concentration was tested on a total sample of 30 adult individuals (at least 14 segments) distributed in 3 trays containing 10 individuals, $20 \mathrm{~mL}$ of artificial saline water (ASW) at $35 \%$ of salinity and specific concentration of BPA. Three trays containing only pure ASW were used as control. We replaced water and treatments every two days in order to reduce the presence of catabolites and to maintain high oxygenation and constant salinity. At the end of each week, we calculated the mortality rate and counted the total number of eggs laid in each tray and the number of eggs laid per individual. Successively, the eggs were removed. At the end of the experiment, after 5 weeks, the average of

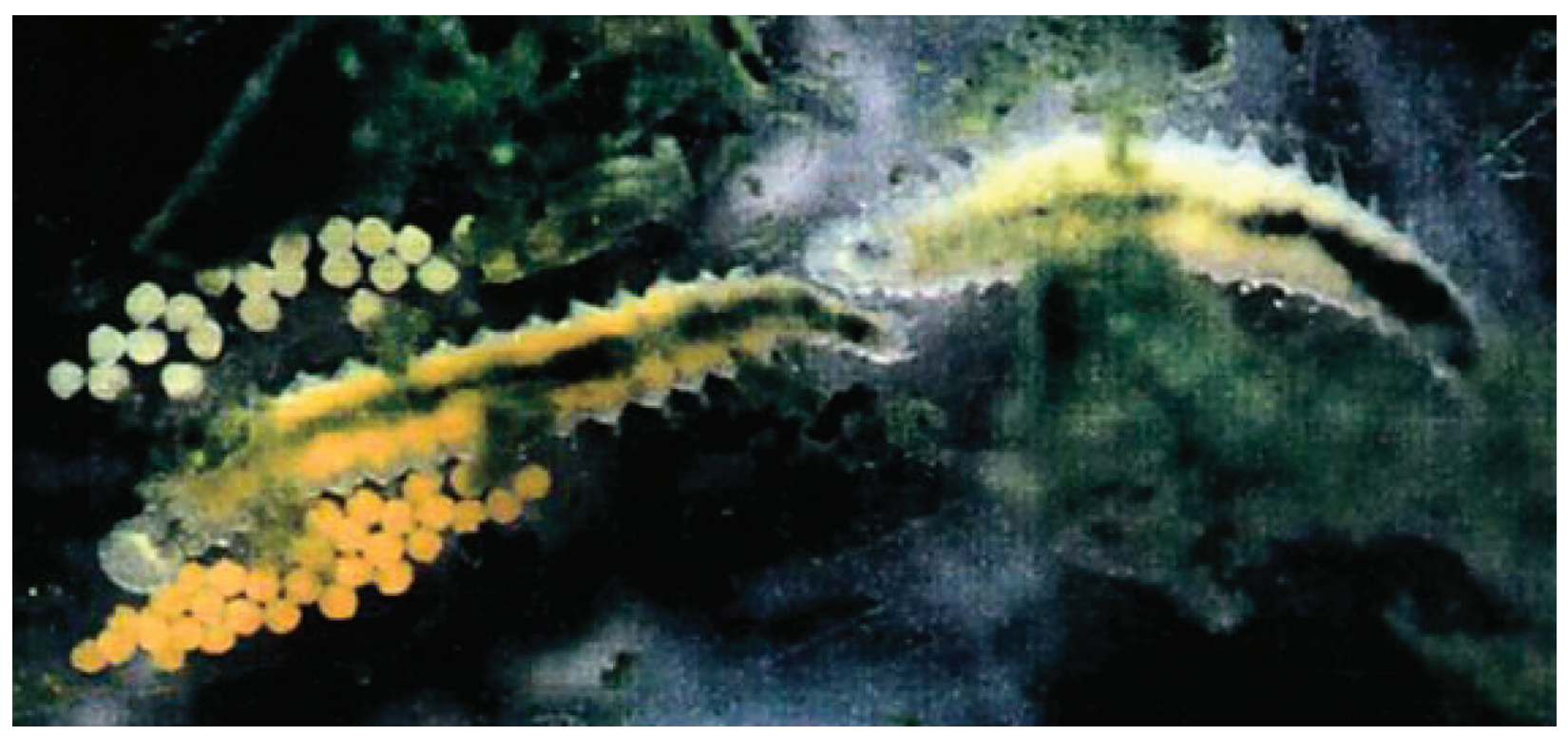

Figure 1. Two adults of Ophryotrocha diadema with 2 egg masses attached to the ends. 
total eggs produced per individual after different BPA concentrations was calculated.

A Shapiro-Wilk test was performed to assess the normality of data distribution. Since the value was nonsignificant $(p=0.14)$, we proceeded with parametric tests. Therefore, we used two-way ANOVA and $t$-test with Bonferroni correction to analyze differences in the reproductive parameters among treatments. In addition, a linear regression was performed in order to evaluate any correlation between the BPA concentrations and the number of laid eggs. All statistical calculations were carried out using the SPSS software package program (version 25.0; SPSS, Inc., Chicago, Illinois, USA). All $\mathrm{P}$-values were two-tailed, and P-values of $5 \%$ or less were considered statistically significant for all tests carried out.

\section{RESULTS}

The average eggs/individual observed after 5 weeks of BPA treatment ranged from 22.3 for controls to 3.3 for the highest BPA concentration of $6.4 \mu \mathrm{M}$. As regards the intermediate concentrations, the average number of eggs/individual was 8.9, 10.6, 18.9, 18.5 and 25.8 for
$3.2 \mu \mathrm{M}, 1.6 \mu \mathrm{M}, 0.8 \mu \mathrm{M}, 0.4 \mu \mathrm{M}$ and $0.2 \mu \mathrm{M}$ concentrations, respectively (Table 1).

The correlation analyses showed a strong negative linear correlation between the BPA concentrations and the number of eggs laid $\left(\mathrm{R}^{2}=0.817 ; p<0.001\right)$ (Figure 2).

The ANOVA test indicated a significant difference in the variance of laid eggs, which averaged over 5 weeks at various concentrations $(p=0.004)$. The differences observed between the averages of the treatments and controls were significant only for the $6.4 \mu \mathrm{M}$ BPA concentrations $(1461.1 \mu \mathrm{g} / \mathrm{L})(p=0.02, t$-test with Bonferroni correction) (Table 1).

\section{DISCUSSION}

In the present study, we analyzed the effects of different BPA concentrations on the reproduction pattern of the polychaete Ophryotrocha diadema. Given its high reproduction rate and short cycle life, this worm represents a useful model in order to evaluate the effect of environmental xenobiotics on the reproduction pattern (Lorenzi and Sella 2008).

Table 1. Statistical applications on the number of eggs produced in relation to BPA concentration. All $p$-values in bold are statistically significant.

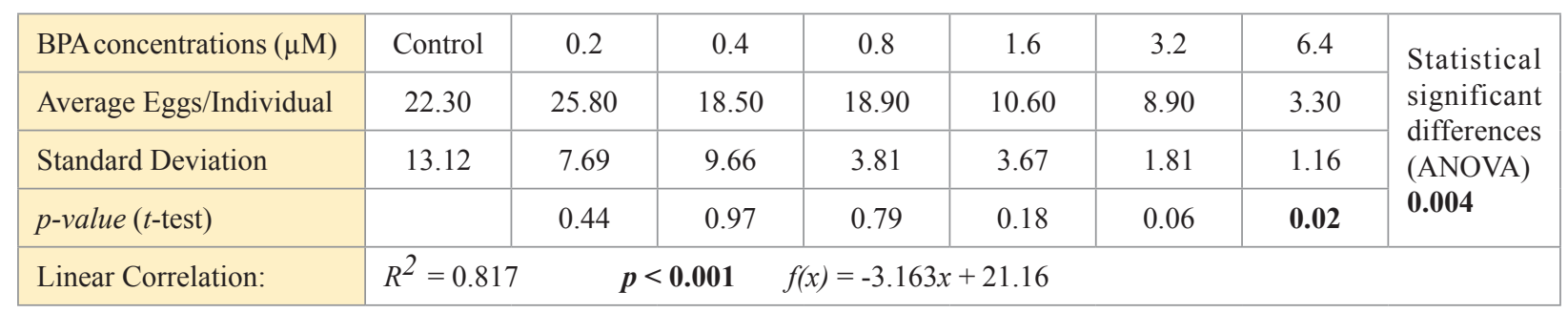

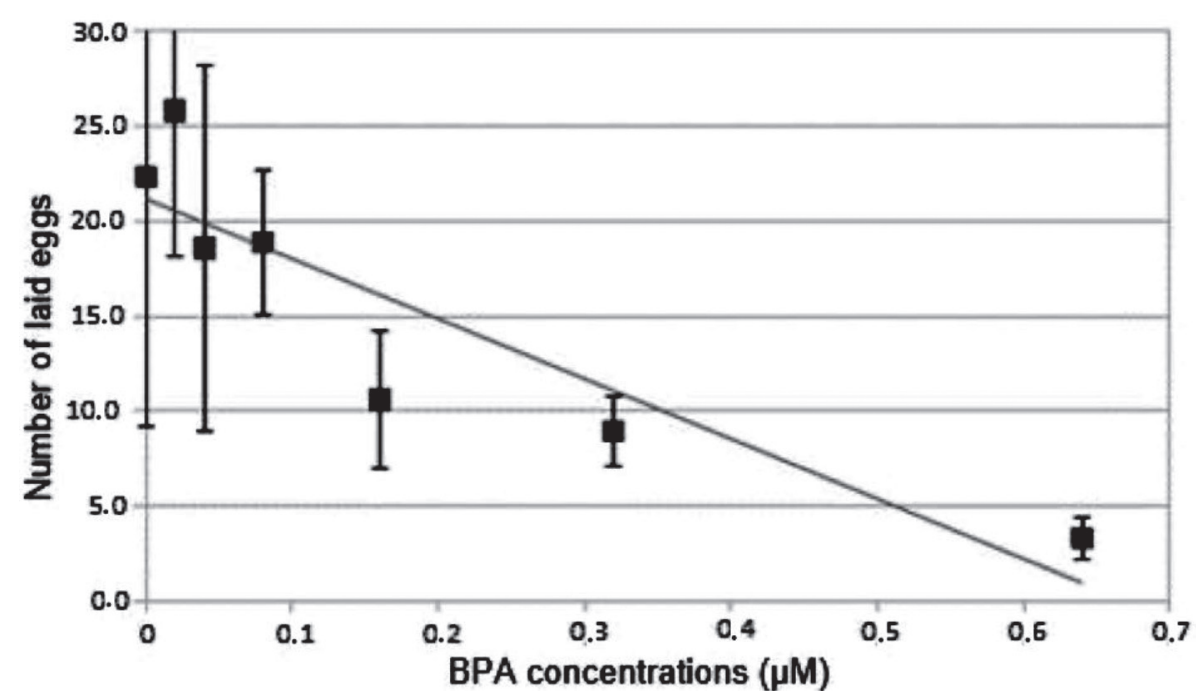

Figure 2. Regression analysis between different BPA concentrations and the number of laid eggs in $O$. diadema $\left(\mathrm{R}^{2}=0.817\right.$; $p<0.001)$. 
As observed for Daphnia magna, a small planktonic cladoceran crustacean (Rehse et al. 2018), also for Ophryotrocha diadema, BPA was found to affect the reproduction rate in a typical dose-dependent manner. However, we found a negative effect of BPA on fertility at concentrations above $6.4 \mu \mathrm{M}(1461.1 \mu \mathrm{g} / \mathrm{L})$ (Table 1), concentrations that are difficult to reach in marine environments (Careghini et al. 2015) but can be found in inland waters located in the vicinities of industrial zones or highly chemically contaminated areas (Fent et al. 2003).

Besides, many types of EDCs, such as phthalates, parabens and BPA, have a very short half-life and can last only hours. This constitutes a limit to the precise estimate of exposure to pesticides and other substances (Isobe et al. 2007). Several authors have reported a similar effect on the reproduction patterns in other marine organisms, although at lower concentrations. For instance, Henrick et al. (1999) found inhibition of the development of larvae of the marine copepod Acartia tonsa exposed to concentrations of $100 \mu \mathrm{g} / \mathrm{L}$ of BPA. The same authors also observed a high mortality and the reduction of egg production at concentrations of $300 \mu \mathrm{g} / \mathrm{L}$ (Henrick et al. 1999). Moreover, the concentration of $300 \mu \mathrm{g} / \mathrm{L}$ BPA was found to induce reduction in fertilization success of the sperms of the sea urchin Paracentrotus lividus (Özlem and Hatice 2008).

The fact that $O$. diadema is commonly found in highly degraded environments could possibly explain its lower susceptibility to environmental pollution. It principally lives amongst the interstitial fauna in nutrient-rich and polluted habitats and, consequently, may have evolved genetic mechanisms able to provide greater resistance to pollutants. This could explain its occurrence in the sampling area (Porto Empedocle, Sicily), which is one of the main harbours in the southern Mediterranean Sea and therefore deeply impacted by merchant and ferry routes.

Finally, it should be emphasized that the accumulation effects caused by endocrine disruptors could also have long-term consequences. For example, in Crassostrea angulata oysters, approximately 160 times more BPA have been found accumulated in the gonads of males and females after exposure to $2 \mathrm{mg} / \mathrm{L}$ of BPA compared to controls (Luo et al. 2017). Consequences of this bioaccumulation, at individual and species level, could also be relevant considering that BPA has been recognized to induce a different expression of genes encoding important proteins such as vitellogenin, periostin and phosphoglucomutase, which are involved in energy metabolism, oxidative stress and regulation of gene transcription (Luo et al. 2017). Moreover, endocrine disruptor compounds were also found to induce a mutational state called "super-feminization", as observed in the ramshorn snails after exposure to $1-100 \mathrm{ug} / \mathrm{L}$ of BPA. A super-female of ramshorn snail is characterized by the addition of sex organs, malformations of the pallial oviduct, enhanced egg production outside the main spawning season, enlarged accessory sex glands and increase of female mortality (Oehlmann et al. 2009).

With this study, we provided evidence for a possible impact of the endocrine disruptor BPA on the reproduction rate of the polychaete $O$. diadema. We found a strong negative linear correlation between the BPA concentrations and the number of laid eggs, although significant effects were observed only at the higher concentrations of $1461.1 \mu \mathrm{g} / \mathrm{L}(6.4 \mu \mathrm{M})$.

These data alone do not seem to cause particular concern. However, it should be emphasized that in the last decades, global production of plastic has continued to rise and, consequently, millions of tons of plastic compounds continue to accumulate in the environment. Most of these compounds are reported to be endocrine disruptors, mimicking or blocking natural hormone action and altering the normal functioning of the endocrine system of invertebrate and mammal species (Damstra et al. 2002). In this scenario, considering the potential population and evolutionary implications, the cumulative effects on the reproduction rate of exposure to different disruptors should be analyzed at different levels of the biome.

\section{ACKNOWLEDGMENTS}

This research was supported by a grant from the Italian Ministry of University and Scientific Research ("ex $60 \%$ "). We are grateful to the reviewers for their suggestions and adjustments. In memory of Cervella P., who is thanked for providing valuable advice and ideas and for several years of research.

\section{CONFLICTS OF INTEREST}

The authors declare no conflict of interest.

\section{ORCID}

Alfredo Santovito https://orcid.org/0000-0001-52925206

Stefano Ruberto https://orcid.org/0000-0001-5478999X

\section{REFERENCES}

Cabaton, N. J., R. W. Perinaaz, V. S. Rubin, D. Zalko, C. M. Schaeberle, M. H. Askenase, J. L. Gadbois, A. P. Tharp, G. S. Whitt, C. Sonnenschein, and M. Soto. 
2011. Perinatal Exposure to Environmentally Relevant Levels of Bisphenol A Decreases Fertility and Fecundity in CD-1 Mice. Environmental Health Perspectives 4: $547-552$.

Cannarsa, E., M. C. Lorenzi, and G. Sella. 2015. Early social conditions affect female afeccundity in hermahrodites. Current Zoology 61: 983-990.

Careghini, A., A. F. Mastorgio, S. Saponaro, and Elena Sezenna. 2015. Bisphenol A, Nonylphenols, Benzophenones, and Benzotriazoles in Soils, Groundwater, Surface Water, Sediments, and Food: A Review. Environmental Science and Pollution Research 22 (8): $5711-41$.

Chen, J., Y. Xiao, Z. Gai, R. Li, Z. Zhu, C. Bai, R. L. Tanguay, X. Xu, C. Huang, and Q. Dong. 2015. Reproductive toxicity of low level bisphenol A exposures in a two-gen-eration zebrafish assay: evidence of malespecific effects. Aquatic Toxicolology 169: 204-214.

Damstra, T., S. Barlow, A. Bergman, R. Kavlock, and G. Van der Kraak. 2002. "Chapter 4. Wildlife". In World Helat Organization, Lobal assessment of the state of the science of endocrine disruptors, 33-50. $\mathrm{WHO} / \mathrm{PCS} / \mathrm{EDC}$.

Diamanti-Kandarakis, E., J. P. Bourguignon, L.C. Giudice, R. Hauser, G. S. Prins, A. M. Soto, R. T. Zoeller, and A. C. Gore. 2009. Endocrine-Disrupting Chemicals: An Endocrine Society Scientific Statement. Endocrine Reviews 30 (4): 293-342.

Durando, M., L. K. J. Piva, C. Sonnenschein, A. M. Soto, E. H. Luque, and M. Muñoz-De-Toro. 2006. Prenatal Bisphenol a Exposure Induces Preneoplastic Lesions in the Mammary Gland in Wistar Rats. Environmental Health Perspectives 115: 80-86.

Fent, G., W. J. Hein, M. J. Moendel, and R. Kubiak. 2003. Fate of 14C-Bisphenol A in Soils. Chemosphere 51 (8): 735-746.

Flint, S., T. Markle, S. Thompson, and E. Wallace. 2012. Bisphenol A Exposure, Effects, and Policy: A Wildlife Perspective. Journal of Environmental Management 15: 19-34.

Fukazawa, H., M. Watanabe, F. Shiraishi, H. Shiraishi, T. Shiozawa, H. Matsushita, and Y. Terao. 2002. Formation of Chlorinated Derivatives of Bisphenol A in Waste Paper Recycling Plants and Their Estrogenic Activities. Journal of Health Science 48: 242-249.

Henrick, R. A., B. Halling-Sørensen, and K. O. Kusk. 1999. A Parameter for Detecting Estrogenic Exposure in the Copepod Acartia Tonsa. Ecotoxicology and Environmental Safety 44: 56-61.

Isobe, T., H. Takada, M. Kanai, S. Tsutsumi, K. O. Isobe, R. Boonyatumanond, and M. P. Zakaria. 2007. Distribution of Polycyclic Aromatic Hydrocarbons (PAHs) and Phenolic Endocrine Disrupting Chemicals in South and Southeast Asian Mussels. Environmental Monitoring and Assessment 135: 423-440.
Karnam, S. S., R. C. Ghosh, S. Mondal, and M. Mondal. 2015. Evaluation of Subacute Bisphenol - A Toxicity on Male Reproductive System. Veterinary World 8 (6): 738-744.

Lemos, M. F. L., C. A. M. Van Gestel, and A. M. V. M. Soares. 2010. Reproductive Toxicity of the Endocrine Disrupters Vinclozolin and Bisphenol A in the Terrestrial Isopod Porcellio Scaber (Latreille, 1804). Chemosphere 78 (7): 907-13.

Lorenzi, M. C., and G. Sella. 2008. A Measure of Sexual Selection in Hermaphroditic Animals: Parentage Skew and the Opportunity for Selection. Journal of Evolutionary Biology 21 (3): 827-33.

Luo, L., Q. Zhang, X. Kong, H. Huang, and C. Ke. 2017. Differential Effects of Bisphenol A Toxicity on Oyster (Crassostrea Angulata) Gonads as Revealed by LabelFree Quantitative Proteomics. Chemosphere 176: 305-314.

Meeker, J. D., S. Sathyanarayana, and S. H. Swan. 2009. Phthalates and Other Additives in Plastics: Human Exposure and Associated Health Outcomes. Philosophical Transactions of the Royal Society B: Biological Sciences 364 (1526): 2097-2113.

Mita, L., M. Bianco, E. Viggiano, F. Zollo, U. Bencivenga, V. Sica, G. Monaco, P. Canciglia, and D. G. Mita. 2011. Bisphenol A Content in Fish Caught in Two Different Sites of the Tyrrhenian Sea (Italy). Chemosphere 82: 405-410.

Oehlmann, J., U. Schulte-Oehlmann, W. Kloas, O. Jagnytsch, I. Lutz, K. O. Kusk, Leah Wollenberger, E. M. Santos, G. C. Paull, K. J. E. Van Look, and C. R. Tyler. 2009. A Critical Analysis of the Biological Impacts of Plasticizers on Wildlife. Philosophical Transactions of the Royal Society B: Biological Sciences 346: 2047-2062.

Özlem, C. A., and P. Hatice. 2008. Effects of Bisphenol A on the Embryonic Development of Sea Urchin (Paracentrotus lividus). Environmental Toxicology 23 (3): 387-392.

Rehse, S., W. Kloas, and C. Zarfl. 2018. Microplastics Reduce Short-Term Effects of Environmental Contaminants. Part I: Effects of Bisphenol a on Freshwater Zooplankton Are Lower in Presence of Polyamide Particles. International Journal of Environmental Research and Public Health 15 (2): 280-295.

Sella, G., and M. C. Lorenzi. 2000. Partner Fidelity and Egg Reciprocation in the Simultaneously Hermaphroditic Polychaete Worm Ophryotrocha Diadema. Behavioral Ecology 11 (3): 260-264.

Wintgens, T., M. Gallenkemper, and T. Melin. 2003. Occurrence and Removal of Endocrine Disrupters in Landfill Leachate Treatment Plants. Water Science and Technology 48 (3): 127-134.

Xie, M., B. Pengli, L. Fengjie, L. Shijian, W. Hongjuan, Y. Lu, and W. Ying. 2016. Neonatal Bisphenol A Expo- 
sure Induces Meiotic Arrest and Apoptosis of Spermatogenic Cells. Oncotarget 7 (9): 10606-10615.

Yamamoto, T. A., A. Yasuhara, H. Shiraishi, and O. Nakasugi. 2001. Bisphenol-A inhazardous landfill leachates. Chemosphere 42: 415-418.

Zhang, Y., C. Mengqian, W. Lang, Z. Guo, and W. Zaizhao. 2016. Bisphenol A Induces Spermatocyte Apoptosis in
Rare Minnow Gobiocypris Rarus. Aquatic Toxicology 179: 18-26.

Zhuang, W., W. Kusheng, W. Yukai, Z. Hongjun, D. Zanzhang, P. Lin, and Z. Guanghui. 2015. Association of Serum Bisphenol-A Concentration and Male Reproductive Function among Exposed Workers. Archives of Environmental Contamination and Toxicology 68: 38-45. 